\title{
Multimorbidity and consultation time: a systematic review
}

\author{
Ana Carolina Reis Tadeu ${ }^{1 *}$ (D), Inês Rosendo Carvalho e Silva Caetano ${ }^{1,2}$, Inês Jorge de Figueiredo ${ }^{1,3,4}$ and \\ Luiz Miguel Santiago ${ }^{1,5,6}$
}

\begin{abstract}
Background: Multimorbidity (MM) is one of the major challenges health systems currently face. Management of time length of a medical consultation with a patient with MM is a matter of concern for doctors.

Methods: A systematic review was performed to describe the impact of MM on the average time of a medical consultation considering the Preferred Reporting Items for Systematic Review and Meta-analyses (PRISMA) guidelines. The systematic online searches of the Embase and PubMed databases were undertaken, from January 2000 to August 2018. The studies were independently screened by two reviewers to decide which ones met the inclusion criteria. (Kappa $=0.84$ and Kappa $=0.82$ ). Differing opinions were solved by a third person. This systematic review included people with MM criteria as participants (two or more chronic conditions in the same individual). The type of outcome included was explicitly defined - the length of medical appointments with patients with MM. Any strategies aiming to analyse the impact of MM on the average consultation time were considered. The length of time of medical appointment for patients without MM was the comparator criteria. Experimental and observational studies were included.
\end{abstract}

Results: Of 85 articles identified, only 1 observational study was included, showing a clear trend for patients with MM to have longer consultations than patients without MM criteria $(p<0.001)$.

Conclusions: More studies are required to better assess allocation length-time for patients with MM and to measure other characteristics like doctors' workload.

Keywords: Multimorbidity, Medical appointment, Quality of healthcare, Consultation length

\section{Background}

Multimorbidity (MM) is defined by the European General Practice Research Network as "any combination of chronic disease with at least one other disease (acute or chronic) or biopsychosocial factor (associated or not) or somatic risk factor" [1]. This is sometimes simplified to, "the simultaneous occurrence of two or more chronic diseases in the same individual" [2]. MM is now one of the main challenges faced by health systems at an international level and occupies a considerable part of the

\footnotetext{
* Correspondence: carolina.r.tadeu@gmail.com

${ }^{1}$ Faculty of Medicine, University of Coimbra, Coimbra, Portugal

Full list of author information is available at the end of the article
}

daily activity of General Practitioners/Family Doctors (GPs/FMs) around the world [3-6].

With an ever-ageing world population, $\mathrm{MM}$ and its consequences, are becoming a major issue in public health and primary care. According to United Nations data $[7,8]$, Europe has the largest percentage of population aged 60 or over (25\%) [7]. In 2015 the number of people in the world aged 60 years and older was 901 million [8]. It is projected that in 2030 this figure will rise to 1.4 billion (a 56\% increase since 2015) and stand at 2.1 billion in 2050 [8]. Several studies have shown that there is a significant association between age [2] and the prevalence of $\mathrm{MM}$, most national health systems not

(c) The Author(s). 2020 Open Access This article is licensed under a Creative Commons Attribution 4.0 International License, which permits use, sharing, adaptation, distribution and reproduction in any medium or format, as long as you give appropriate credit to the original author(s) and the source, provide a link to the Creative Commons licence, and indicate if changes were made. The images or other third party material in this article are included in the article's Creative Commons licence, unless indicated otherwise in a credit line to the material. If material is not included in the article's Creative Commons licence and your intended use is not permitted by statutory regulation or exceeds the permitted use, you will need to obtain permission directly from the copyright holder. To view a copy of this licence, visit http://creativecommons.org/licenses/by/4.0/ The Creative Commons Public Domain Dedication waiver (http://creativecommons.org/publicdomain/zero/1.0/) applies to the data made available in this article, unless otherwise stated in a credit line to the data. 
being prepared or able to cope with this rapid ageing with many demands $[5,6]$. MM reduces life expectancy and quality of life (QoL) [5]. However, QoL can increase if the quality of care (QoC) improves [9], and this can require additional consultation time.

So, it is imperative to think about the most correct approach to patients with MM in order to maximize the QoC provided by the Health Services (HS), and so ensure a better quality of life.

GPs/FMs medical team face various difficulties in caring for a patient with MM like lack of resources; consultation time restrictions [10]; lack of interdisciplinary care/teams; inadequate patient support (largely relying on community-based support services); inadequate tools (guidelines are drawn up strictly for specific diseases and not for the MM patient); the attitude of the patient (often discouraged and poorly engaged) $[4,11]$.

Information about the length-time of a consultation with a patient with $\mathrm{MM}$ is essential to better organize and deliver healthcare. To our knowledge, no previous review has summarized data related to: What is the impact of having MM on the medical consultation?; and Is the average length-time consultation with a patient with MM longer than for a patient without MM?.

\section{Methods}

A systematic review was performed considering the Preferred Reporting Items for Systematic Review and MetaAnalyses (PRISMA) guidelines for systematic reviews and meta-analysis, not following any review protocol. This research proposal has been submitted to and approved by the Faculty of Medicine at the University of Coimbra.

\section{Eligibility criteria}

The PICO model has been followed to define the question and allow the most effective literature search. The population (P) was defined as people with MM. The most widely used definition of MM was used, which is the coexistence of two or more chronic conditions in the same individual [2]. The World Health Organization (WHO) definition of chronic disease was adopted, namely, health problems that require ongoing care over a long period of time (years or decades) [12].

As interventions (I) any strategies aiming to analyse the impact of $\mathrm{MM}$ on the average consultation time were considered. The length of time of medical appointment for patients without MM was the comparator criterion $(\mathrm{C})$. As outcome $(\mathrm{O})$, it was expected to explicitly define the length-time of medical appointments with patients with MM. Experimental and observational studies were included. Studies which did not specify the time spent on medical appointments were excluded.

\section{Information sources and search strategy}

The systematic online searches were implemented using combinations of keywords in the following electronic databases: the Embase and PubMed databases, from January 1, 2000 until August 31, 2018, an 18-year time period, to find pertinent studies. The authors believe that the most reliable way to assess consultation time is through computerized clinical records, which were very scarce before 2000 .

The search within the Embase database used the following combination of keywords: ('multiple chronic conditions'/exp. OR'multiple chronic conditions') AND ('consultation time' OR (('consultation'/exp. OR consultation) AND ('time'/exp. OR time))); ('multiple chronic conditions'/exp. OR 'multiple chronic conditions') AND ('primary health care'/exp. OR 'primary health care') AND ('time'/exp. OR time); 'consultation'/exp. AND 'multiple chronic conditions'/exp./mj; 'multiple chronic conditions'/exp. AND ('time'/exp. OR'average'/exp. OR 'consultation'/exp). For the PubMed database the combinations of keywords were: "Chronic Disease/epidemiology"[Mesh] AND (("referral and consultation" [MeSH Terms] OR ("referral"[All Fields] AND "consultation"[All Fields]) OR "referral and consultation"[All Fields] OR "consultation"[All Fields]) AND ("time" [MeSH Terms] OR "time"[All Fields])).

The search was limited to papers in English, Portuguese, Spanish and French published in internationallyrecognized peer-reviewed journals to ensure the reliability of the data. No other limits were imposed during this stage of the study. References in the identified literature were scanned for further literature when it was found appropriate to support work decisions.

\section{Data extraction and quality assessment}

The potentially relevant studies containing quantitative consultation time data were selected in two stages. First, the titles and abstracts quoted in the literature search were independently screened by two reviewers (the first and third co-authors of this work) to decide which ones to accept, meeting the inclusion criteria $($ Kappa $=0.84)$. Those not meeting the inclusion criteria were excluded. Differing opinions on a study's inclusion were resolved by a third person (the second co-author of this work).

Secondly, the researchers independently read and analysed the integrity of the matching studies and tried to reach an agreement concerning eligibility $($ Kappa $=0.82)$. Those not meeting the inclusion criteria were excluded. Differing opinions on a study's inclusion were resolved by a third person (the second co-author of this work). The quality and risk of bias of the included studies was assessed using the Newcastle-Ottawa Scale (NOS), more precisely, the Newcastle-Ottawa scale adapted for crosssectional studies [13]. The NOS is widely used and 
recommended by the Cochrane Collaboration [14], and the authors found it suitable for the purpose of this work. This tool assesses three aspects of a study: the selection of the sample; the comparability of the groups; and the outcome (assessment of outcome and statistical test). It is composed of 7 items and classifies the study in 4 possible levels: Very good (9-10 points), Good (7-8 points), Satisfactory (5-6 points) and Unsatisfactory (04 points). Any disagreement was resolved through consensus.

This systematic review was conducted using Covidence 13, the standard production platform used for Cochrane reviews, which was used for the data and records management.

\section{Outcomes and statistical analysis}

The patients were split into two groups, those with and those without MM, and the relative frequencies were calculated. The results were analysed using the chisquare distribution test.

\section{Results}

\section{Study selection}

As described in Fig. 1, the electronic database searches started with 85 potentially eligible references (16 in PubMed and 59 in Embase). Of these, 5 were duplicates and were thus excluded and 31 were considered irrelevant based on a review of the title and abstract. The remaining studies were fully read, analysed and assessed for eligibility; 36 were then excluded due to unsatisfactory outcome [3,16-49], 5 due to unsuitable study design [50-54], 4 due to unsuitable patient population [11, 55-57], 2 due to inadequate language $[58,59]$ and 1 to unsatisfactory setting [60]. In the end, 1 study was included [61].

\section{Study characteristics and quality}

The main relevant features and outputs of the study were extracted for the purpose of this systematic review and are summarized in Table 1.

The included study was conducted between 2008 and 2009 in Denmark, over 12 months. It involved 404 general practitioners (GPs) participants and a total of 8236 contacts. It included patients aged 40 years or more, grouped as those without any chronic condition and those with one, two, three or more chronic conditions.

During the study period, the GPs completed a onepage registration form for each of their patient contacts. Of the various items that were registered, the ones relevant for this review were information on chronic diseases and length-time of consultation. Quality assessment result, performed as described in methodology, is presented in Table 2. The quality of the study was considered satisfactory (score 6 out of a maximum score

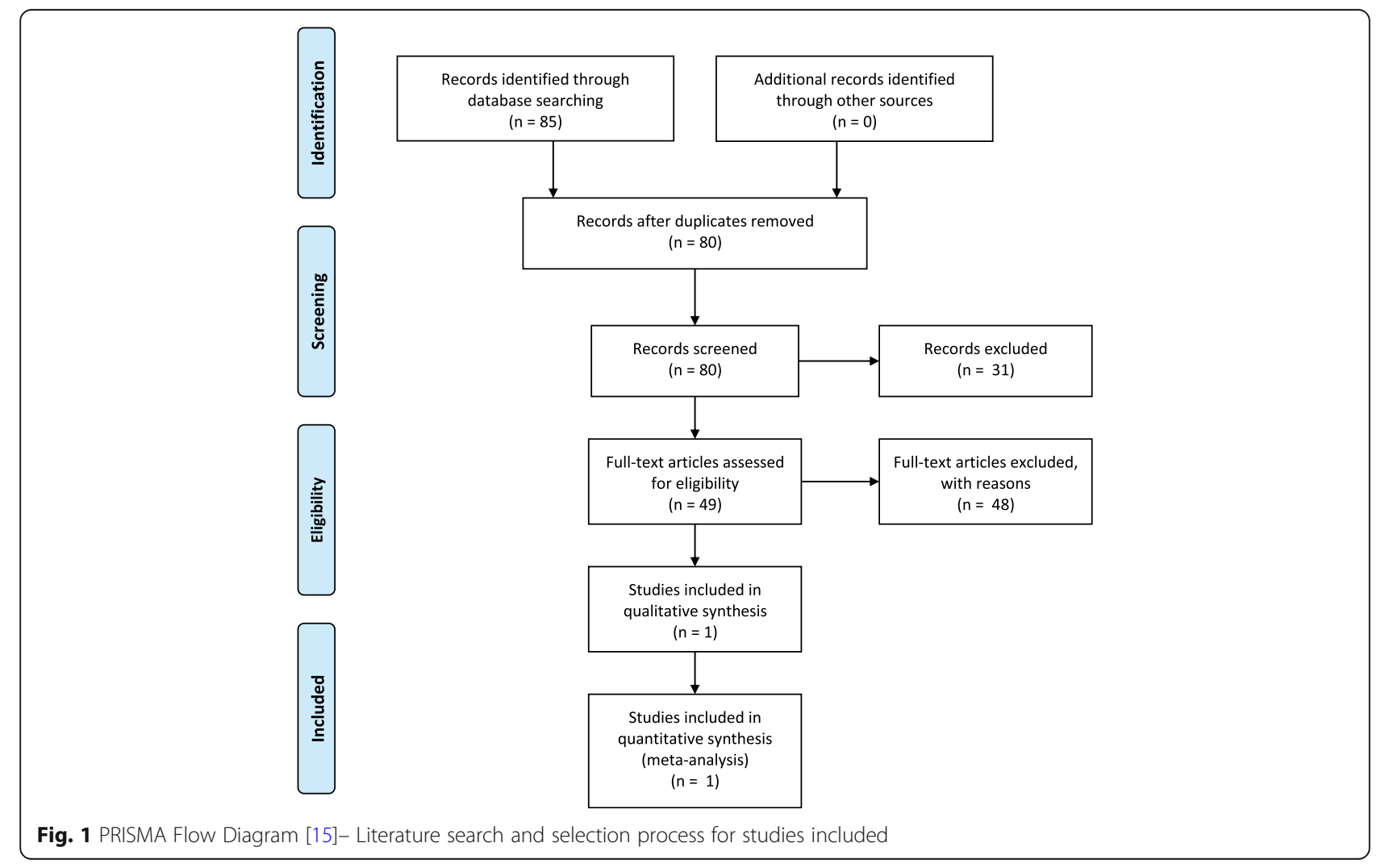




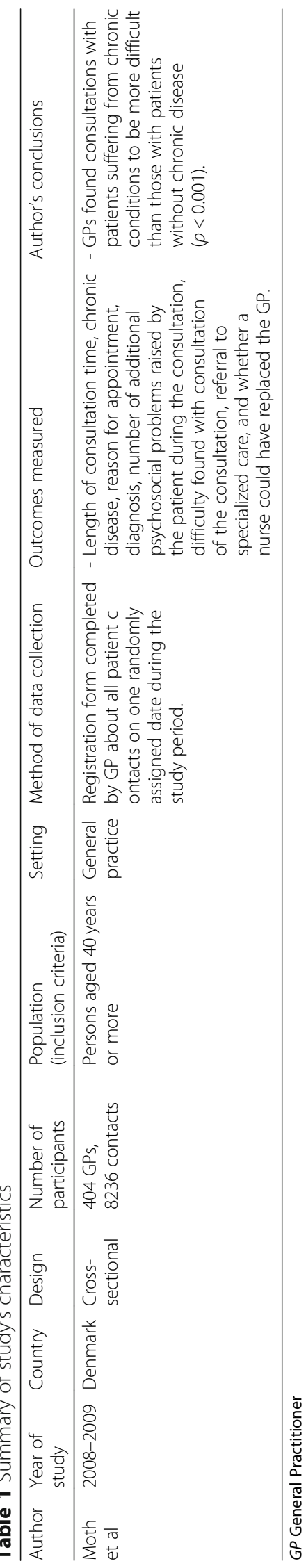


Table 2 Quality of study - Newcastle-Ottawa Scale adapted for cross-sectional studies

\begin{tabular}{|c|c|c|c|c|c|c|c|c|c|}
\hline \multirow[t]{2}{*}{ Author } & \multicolumn{4}{|l|}{ Selection } & \multirow{2}{*}{$\begin{array}{l}\text { Comparability } \\
\text { Comparability of subjects in } \\
\text { different outcome groups on } \\
\text { the basis of design or analysis. }\end{array}$} & \multicolumn{2}{|l|}{ Outcome } & \multirow{2}{*}{$\begin{array}{l}\text { Total } \\
\text { score }\end{array}$} & \multirow[t]{2}{*}{ Power } \\
\hline & $\begin{array}{l}\text { Representativeness } \\
\text { of the sample }\end{array}$ & $\begin{array}{l}\text { Sample } \\
\text { size }\end{array}$ & $\begin{array}{l}\text { Non- } \\
\text { respondents }\end{array}$ & $\begin{array}{l}\text { Ascertainment } \\
\text { of exposure } \\
\text { (risk factor) }\end{array}$ & & $\begin{array}{l}\text { Assessment } \\
\text { of outcome }\end{array}$ & $\begin{array}{l}\text { Statistical } \\
\text { test }\end{array}$ & & \\
\hline $\begin{array}{l}\text { Moth } \\
\text { et al }\end{array}$ & * & - (b) & * & $* *$ & - (c) & * & * & 6 & Satisfactory \\
\hline
\end{tabular}

of 10), its main weakness being in the comparability section.

\section{Results of study}

Table 3 shows the relationship between the length of consultation time and the type of patient (with and without MM). There is a clear significant trend for patients with $\mathrm{MM}$ to have longer consultations than patients without MM $(p<0.001)$.

More than $25 \%$ of MM patients had a consultation length-time of at least $16 \mathrm{~min}$ while more than $75 \%$ of the patients without MM had a consultation length-time under $15 \mathrm{~min}$. Length-time consultation on both types of patients is more frequently between 6 and $15 \mathrm{~min}$. There is a significant difference, however, in the percentage of patients with $\mathrm{MM}$ requiring more time than patients without MM criteria.

\section{Discussion}

\section{Main findings}

The present systematic review sought to find out if the average consultation time spent on patients with $M M$ is longer than that spent on patients who do not meet the MM criteria. It could only identify one study [61], undertaken in Denmark, in which the consultation time was logged as a function of the number of chronic diseases. This study revealed a tendency for consultations to take longer for patients with MM than for those without MM. However, the study was not directly aimed at answering this question and it did not take confounding factors into account. In addition, it does not describe the calculation to determine the sample size of the study and it could be inaccurate to study this specific outcome still it answers the posed question.

Table 3 Length of consultation time and type of patient (with and without MM criteria)

\begin{tabular}{llllll}
\hline Length of consultation time & $\begin{array}{l}\text { No MM } \\
\text { (n) \% }\end{array}$ & \multicolumn{3}{l}{$\begin{array}{l}\text { MM } \\
(\mathrm{n}) \%\end{array}$} & $p$-value \\
\hline$<5$ min & 293 & 11.7 & 96 & 7.7 & $p<0.001$ \\
$6-15$ min & 1686 & 67.3 & 804 & 64.9 & \\
$16-30$ min & 485 & 19.4 & 314 & 25.3 & \\
$>30$ min & 42 & 1.7 & 25 & 2.0 & \\
Total & 2506 & 100 & 1239 & 100 & \\
\hline
\end{tabular}

\section{Comparison with existing literature}

The small number of publications in the literature on this subject shows that more studies should be designed to investigate the impact of MM on the consultation length-time. It is vital to analyse this issue in order to manage resources so that they meet the actual need, and to ensure the services provided by health services, national or private, are appropriate. It will thus be possible to guarantee better quality health services and outcomes for these patients. In fact, MM is about a patient with more than two chronic diseases or one chronic disease with biopsychosocial factor (associated or not) or somatic risk factor, so illness being included and not only about the specific sufferances $[1,11]$.

In studies with calculated size population representative random samples it is important that accurate methods are used to measure the real length-time of a consultation using appropriate tools. Confounding factors must be eliminated as the time spent on administrative work. Only direct observation using video recording has been proven to obtain accurate values when measuring the duration of consultations [62], which could be a procedure that mitigates many of the errors previously mentioned. It is essential to identify beforehand any possible confounding factors inherent to the patients (for example, hearing difficulty, education level, age, socio-economic level), inherent to the doctor (in particular, a change in behaviour due to the participation in the research study - Hawthorne effect [63]), and inherent to the consultation/institution (for example, glitches in computer systems, organization of necessary information in the health informatics records, coding errors, telephone call interruptions). The time lost searching for information in consultation, the friendliness of clinical informatics and the time spent on records are also issues to be studied and thought of $[64,65]$. Health determinants are factors to be studied in such a MM population for better health and social outcomes [66].

The data analysis must be evaluated using objective validated laboratory methods and, if possible, it should be a blind assessment. Statistical tests used to analyse the data must be appropriate and clearly described. Measures of association, including confidence intervals and the $P$ value, must be presented. 


\section{Further considerations}

The QoL of MM patients can increase if the quality of QoC improves, so the improvement of the quality of services provided by the HS is an important matter.

Patients with MM require more medical resources and longer consultation length. Medical teams need to be interdisciplinary and guidelines drawn up for specific diseases need to be improved for MM patients.

HS need to provide good patient support and to acquire knowledge to deal with often discouraged and poorly engaged patients.

The appropriate length for a consultation of a patient with MM needs to be taken into account to better organize and deliver healthcare, taking into account that the frequency of consulting and the number of problems to discuss are significantly higher in the patients with MM [67].

\section{Strengths and limitations}

The main limitation of this systematic review was the difficulty in ensuring that all the relevant literature was included. Even though the research used two of the main databases - PubMed and Embase - there could be other relevant material in grey literature, not taken into account in the present work to ensure the reliability of the data.

The scarcity of the literature that was found was a limitation for this review. The one publication found, besides not directly answering our question, also does not take confounding factors into account, and does not describe the calculation to determine the sample size of the study. However, it does highlight the relevance of the subject matter. The authors believe that the lack of recognition of $\mathrm{MM}$ and fragile patients in the clinical management of patients is also one of the reasons why scientific research has paid less attention to MM.

\section{Conclusions}

This impact of MM on the duration of a consultation has hardly been studied, this systematic review shows.

A tendency for consultations of patients with MM to take longer than those without MM was found in the only one study with "satisfactory" quality which met the inclusion criteria.

So more research is needed to acquire more information on this subject, important to deal not only with diseases but with the person suffering from MM for consultation must have the adequate length duration to enable doctors and stake-holders with a proper quantification of the time and associated costs.

If a longer consultation time is confirmed, it will be important to rethink and adapt GPs' lists of patients in order to achieve better medical care providing agendas with specific times and allocating enough time for all the required tasks.

\section{Abbreviations}

MM: Multimorbidity; QoL: Quality of life; QoC: Quality of care; GP: General Practitioner; PRISMA: Preferred Reporting Items for Systematic Review and Meta-analyses; HS: Health Service; WHO: World Health Organization

\section{Acknowledgements}

Helena Donato, MD for her valuable contribution in the literature search.

\section{Authors' contributions}

ACRT: Data extraction, data examination, treatment of data, writing of manuscript and its scientific criticism as well as approval. IRCSC: Data extraction, data examination, treatment of data, writing of manuscript and its scientific criticism as well as approval. IJF: Data examination, treatment of data, writing of manuscript and its scientific criticism as well as approval. LMS: Data gathering and analysis, and manuscript writing, scientific revision and approval. All authors have read and approved the final manuscript.

\section{Funding}

No funding or sponsorship was received for this study or publication of this article.

\section{Availability of data and materials}

Materials can be assessed upon request.

Ethics approval and consent to participate

This study has been approved by the Pedagogic Council of the Faculty of Medicine of the University of Coimbra and its Dean.

\section{Consent for publication}

Not applicable.

\section{Competing interests}

No author states financial and non-financial competing interests for this work.

\section{Author details}

${ }^{1}$ Faculty of Medicine, University of Coimbra, Coimbra, Portugal. ${ }^{2}$ USF Coimbra Centro, Coimbra, Portugal. ${ }^{3}$ ACeS Dão Lafões, Coimbra, Portugal. ${ }^{4}$ Faculty of Health Sciences, University of Beira Interior, Covilhã, Portugal. ${ }^{5}$ General Practice/Family Practice clinic of the Faculty of Medicine of University of Coimbra, Coimbra, Portugal. ${ }^{6}$ Center for Health and Investigation studies of the University of Coimbra (CEISUC), Coimbra, Portugal.

Received: 10 October 2019 Accepted: 12 July 2020

Published online: 28 July 2020

\section{References}

1. Le Reste JY, Nabbe P, Manceau B, Lygidakis C, Doerr C, Lingner H, et al. The European general practice research network presents a comprehensive definition of multimorbidity in family medicine and long term care, following a systematic review of relevant literature. J Am Med Dir Assoc. 2013;14(5):319-25

2. Violan C, Foguet-Boreu Q, Flores-Mateo G, Salisbury C, Blom J, Freitag M, et al. Prevalence, determinants and patterns of multimorbidity in primary care: a systematic review of observational studies. PLoS One. 2014;9(7): e102149.

3. Glynn LG, Valderas JM, Healy P, Burke E, Newell J, Gillespie P, et al. The prevalence of multimorbidity in primary care and its effect on health care utilization and cost. Fam Pract. 2011;28(5):516-23.

4. Moffat K, Mercer SW. Challenges of managing people with multimorbidity in today's healthcare systems. BMC Fam Pract. 2015;16:129.

5. Azais B, Bowis J, Wismar M. Facing the challenge of multimorbidity. J Comorb. 2016:6(1):1-3.

6. Navickas R, Petric VK, Feigl AB, Seychell M. Multimorbidity: what do we know? What should we do? J Comorb. 2016;6(1):4-11.

7. United Nations. Department of Economic and Social Affairs, Population Division. In: World Population Prospects: The 2017 Revision, Key Findings and Advance Tables; 2017. p. 11.

8. United Nations, Department of Economic and Social Affairs, Population Division (2015). World Population Ageing. 2015. (ST/ESA/SER.A/390). 
9. Fortin M, Lapointe L, Hudon C, Vanasse A, Ntetu AL, Maltais D. Multimorbidity and quality of life in primary care: a systematic review. Health Qual Life Outcomes. 2004;2:51

10. Salisbury C, Man MS, Bower P, Guthrie B, Chaplin K, Gaunt DM, et al. Management of multimorbidity using a patient-centred care model: a pragmatic cluster-randomised trial of the 3D approach. Lancet. 2018; 392(10141):41-50.

11. Prazeres F, Santiago L. The Knowledge, Awareness, and Practices of Portuguese General Practitioners Regarding Multimorbidity and its Management: Qualitative Perspectives from Open-Ended Questions. Int J Environ Res Public Health. 2016;13(11):1097. https://doi.org/10.3390/ ijerph13111097.

12. World Health Organization. Innovative care for chronic conditions: building blocks for action. Global report: World Health Organ. 2002. https://www. who.int/chp/knowledge/publications/icccglobalreport.pdf?ua=1.

13. Lo CK, Mertz D, Loeb M. Newcastle-Ottawa scale: comparing reviewers' to authors' assessments. BMC Med Res Methodol. 2014;14:45.

14. Higgins JPT, Green S (editors). Cochrane Handbook for Systematic Reviews of Interventions Version 5.1.0 [updated March 2011]. The Cochrane Collaboration; 2011. Available from www.handbook.cochrane.org.

15. Moher D, Liberati A, Tetzlaff J, Altman DG, The PRISMA Group. Preferred reporting items for systematic reviews and meta-analyses: the PRISMA statement. PLoS Med. 2009;6(7): e1000097. https://doi.org/10.1371/journal. pmed.1000097.

16. Tinetti ME, Naik AD, Dodson JA. Moving from disease-centered to patient goals-directed Care for Patients with Multiple Chronic Conditions: patient value-based care. JAMA Cardiol. 2016;1(1):9-10.

17. Gunturi N, Gunturi N, Gennari A, Bartels K. Patient-centered Goals of Care: Using the Chronic Care Management (CCM) Code Towards Cooperative Goal Setting in the Multimorbid Elderly. The Journal of Post-Acute and Long-Term Care Medicine. QUALITY IMPROVEMENT. 2018:19(3):PB20.

18. Johnson TL, Kaldor J, Falster MO, Sutherland K, Humphries J, Jorm LR, et al. Predictive risk modelling under different data access scenarios: who is identified as high risk and for how long? BMJ Open. 2018;8. https://doi.org/ 10.1136/bmjopen-2017-018909.

19. Kangovi S, Carter T, Charles D, Smith RA, Glanz K, Long JA, et al. Toward a scalable, patient-centered community health worker model: adapting the IMPaCT intervention for use in the outpatient setting. Popul Health Manag. 2016;19(6):380-8.

20. Mann EG, Johnson A, VanDenKerkhof EG. Frequency and characteristics of healthcare visits associated with chronic pain: results from a populationbased Canadian study. Can J Anaesth. 2016;63(4):411-41.

21. Palmer K, Onder G. Comprehensive geriatric assessment: benefits and limitations. Eur J Intern Med. 2018;54:e8-9.

22. Rosbach M, Andersen JS. Patient-experienced burden of treatment in patients with multimorbidity - a systematic review of qualitative data. PLoS One. 2017;12(6):e0179916.

23. Salisbury C, Johnson L, Purdy S, Valderas JM, Montgomery AA. Epidemiology and impact of multimorbidity in primary care: a retrospective cohort study. Br J Gen Pract. 2011;61(582):e12-21.

24. Sampalli T, Desy M, Dhir M, Edwards L, Dickson R, Blackmore G. Improving wait times to care for individuals with multimorbidities and complex conditions using value stream mapping. Int J Health Policy Manag. 2015; 4(7):459-66.

25. Smith SM, Soubhi H, Fortin M, Hudon C, O'Dowd T. Managing patients with multimorbidity: systematic review of interventions in primary care and community settings. BMJ. 2012;345:e5205

26. Stokes T, Tumilty E, Doolan-Noble F, Gauld R. Multimorbidity, clinical decision making and health care delivery in New Zealand primary care: a qualitative study. BMC Fam Pract. 2017;18(1):51.

27. Tetzlaff J, Junius-Walker U, Muschik D, Epping J, Eberhard S, Geyer S. Identifying time trends in multimorbidity — defining multimorbidity in times of changing diagnostic practices. J Public Health. 2016;25(2):215-22.

28. Wong ES, Rosland AM, Finn SD, Nelson KM. Patient-centered medical home implementation in the veterans health administration and primary care use: differences by patient comorbidity burden. J Gen Intern Med. 2016;31(12): 1467-74.

29. European General Practice Research Network (EGPRN) Abstracts from the EGPRN meeting in Leipzig, Germany, 12-16 October 2016. Theme: 'General practice/family medicine in a changing world'. Eur J Gen Pract. 2017;23(1): 143-54. https://doi.org/10.1080/13814788.2017.1300653.
30. Abraham-Kaba A, Stopol C. Survivorship continuum: implications for patientcentered programming. J Psychosoc Oncol. 2016;34(1-2):125-7.

31. Stefanacci RG, Cusack CL. The long-term care team of the future. Annals of Long-Term Care. Clinical Care and Aging. 2016;24(4):17-20.

32. Blomgreen J, Ekmann A, Nygaard H, Demény AK, Wejse MR, Pressel E. Geriatric assessment at the acute medical unit: improving the outcome. European Geriatric Medicine. 2017;8(1):s153.

33. Scheiner SR, Olson JM, Velner J. Collaborative drug therapy management in a skilled nursing facility to improve transitions of care in older adults. Pharmacotherapy. 2017;37(12):e221-2.

34. Osborn R, Moulds D, Schneider EC, Doty MM, Squires D, Sarnak DO. Primary care physicians in ten countries report challenges caring for patients with complex health needs. Health Aff. 2015;34(12):2104-12.

35. Bower P. Better management of multimorbidity: a critical look at the 'Ariadne principles'. BMC Med. 2014;12:222.

36. Cassil A. Innovations in preventing and managing chronic conditions: what's working in the real world? Issue brief. 2010;132:1-4.

37. Porter I, Valderas JM. Development of a feedback form for routine clinical use of PROs in primary care for patients with multimorbidity. Qual Life Res. 2015;24(1):181-2.

38. Ehman KM, Deyo-Svendsen M, Merten Z, Kramlinger AM, Garrison GM. How preferences for continuity and access differ between multimorbidity and healthy patients in a team care setting. J Prim Care Community Health. 2017:8(4):319-23.

39. Vasquez AH, Patel $\mathrm{N}$, Tripathy $\mathrm{C}$, Jaen $\mathrm{C}$. Optimizing virtual care to improve access and quality of care. J Am Geriatr Soc. 2018;66(2):109.

40. Fisher K, Griffith L, Gruneir A, Panjwani D, Gandhi S, Sheng LL, et al. Comorbidity and its relationship with health service use and cost in community-living older adults with diabetes: a population-based study in Ontario. Canada Diabetes Res Clin Pract. 2016:122:113-23.

41. Hien H, Ouedraogo M, Berthe A, Konate B, Toe N, Drabo MK, et al. Patient complaints: an opportunity to improve the quality of care of older people with multimorbidity in Burkina Faso. Pan Afr Med J. 2017;28:140.

42. Junius-Walker U, Voigt I, Wrede J, Hummers-Pradier E, Lazic D, Dierks ML. Health and treatment priorities in patients with multimorbidity: report on a workshop from the European general practice network meeting 'Research on multimorbidity in general practice'. Eur J Gen Pract. 2010;16(1):51-4.

43. Kadam UT, Croft PR, North Staffordshire GPCG. Clinical multimorbidity and physical function in older adults: a record and health status linkage study in general practice. Fam Pract. 2007;24(5):412-9.

44. Strauss $\mathrm{VY}$, Jones PW, Kadam UT, Jordan KP. Distinct trajectories of multimorbidity in primary care were identified using latent class growth analysis. J Clin Epidemiol. 2014;67(10):1163-71.

45. van Dongen JJ, Lenzen SA, van Bokhoven MA, Daniels R, van der Weijden T, Beurskens A. Interprofessional collaboration regarding patients' care plans in primary care: a focus group study into influential factors. BMC Fam Pract. 2016;17:58.

46. Lam CLK, Calvert MJ, Valderas JM, Wee HL, Gibbons C. Routine applications of patient reported outcomes (PROs) in primary care: identifying and overcoming the challenges. Qual Life Res. 2016;25(1):9.

47. Potter C, Hunter C, Kelly L, Gibbons E, Forder J, Coulter A, Fitzpatrick R, Peters M. PROs for personalized care: patient perspectives on potential use of the long-term conditions questionnaire (LTCQ) in clinical practice. Qual Life Res. 2016;25(1):196.

48. Jowsey T, McRae IS, Valderas JM, Dugdale P, Phillips R, Bunton R, et al. Time's up. descriptive epidemiology of multi-morbidity and time spent on health related activity by older Australians: a time use survey. PLoS One. 2013:8(4):e59379.

49. Deruaz-Luyet A, N'Goran AA, Tandjung R, Frey P, Zeller A, Haller DM, et al. Multimorbidity in primary care: protocol of a national cross-sectional study in Switzerland. BMJ Open. 2015;5(10):e009165.

50. Oliver D. David Oliver: A manifesto for multimorbidity. BMJ. 2018;360:k1044.

51. Feather A. Managing patients with multimorbidity. Medicine. 2018;46(7): 397-401.

52. Kadam U. Redesigning the general practice consultation to improve care for patients with multimorbidity. BMJ. 2012;345:e6202.

53. Wise J. Patients with multimorbidity need longer GP consultations, says RCGP. BMJ. 2016:355:15961.

54. Loeb DF, Bayliss EA, Candrian C, De Gruy FV, Binswanger IA. Treating complex patients in primary care: physician offer a new view of competing demands. J Gen Intern Med. 2013;28(1):S224-5. 
55. Bower P, Macdonald W, Harkness E, Gask L, Kendrick T, Valderas JM, et al. Multimorbidity, service organization and clinical decision making in primary care: a qualitative study. Fam Pract. 2011;28(5):579-87.

56. Irving G, Neves AL, Dambha-Miller H, Oishi A, Tagashira H, Verho A, et al. International variations in primary care physician consultation time: a systematic review of 67 countries. BMJ Open. 2017;7(10):e017902.

57. O'Malley AS, Sarwar R, Keith R, Balke P, Ma S, McCall N. Provider experiences with chronic care management (CCM) services and fees: a qualitative research study. J Gen Intern Med. 2017;32(12):1294-300.

58. Klement A, Oemler M, Wienke A, Richter M, Wolfradt U. (Expected) consultation length, mental (co-)morbidity and patient satisfaction in the family practice encounter. Z Evid Fortbild Qual Gesundhwes. 2015;109(8):560-9.

59. Mühlhäuser U, Götz K, Weinmayr L-M, Steinhäuser J. DEGAM-guideline "multimorbidity" - a field test. Zeitschrift fur Allgemeinmedizin. 2018;94(2): 64-9.

60. Gruneir A, Dhalla IA, van Walraven C, Fischer HD, Camacho X, Rochon PA, et al. Unplanned readmissions after hospital discharge among patients identified as being at high risk for readmission using a validated predictive algorithm. Open Med. 2011;5(2):E104-11.

61. Moth G, Vestergaard M, Vedsted P. Chronic care management in Danish general practice--a cross-sectional study of workload and multimorbidity. BMC Fam Pract. 2012;13:52

62. Pringle M, Stewart-Evans $C$. Does awareness of being video recorded affect doctors' consultation behaviour? Br J Gen Pract. 1990;40:455-8.

63. Holden JD. Hawthorne effects and research into professional practice. J Eval Clin Pract. 2001;7:65-70.

64. https://ecamfic.wordpress.com/2018/10/21/documento-de-posicionamientosobre-el-hiperregistro-registritis-en-el-encuentro-clinico-profesional-pacienteen-la-atencion-primaria- ap/. [Assessed the 11th September 2019].

65. Laranjo L, Dunn AG, Tong HL, Kocaballi AB, Chen J, Bashir R, et al. Conversational agents in healthcare: a systematic review. J Am Med Inform Assoc. 2018;25(9):1248-58.

66. Veja PB, Losi S, Martinez LS, Bovell-Ammon A, Garg A, James T, et al. Implementing an EHR-based screening and referral system to address social determinants of health in primary care. Med Care. 2019;57:S133-9.

67. Mercer SW, Zhou Y, Humphris GM, McConnachie A, Bakhshi A, Bikker A, et al. Multimorbidity and socioeconomic deprivation in primary care consultations. Ann Fam Med. 2018;16(2):127-31.

\section{Publisher's Note}

Springer Nature remains neutral with regard to jurisdictional claims in published maps and institutional affiliations.

Ready to submit your research? Choose BMC and benefit from:

- fast, convenient online submission

- thorough peer review by experienced researchers in your field

- rapid publication on acceptance

- support for research data, including large and complex data types

- gold Open Access which fosters wider collaboration and increased citations

- maximum visibility for your research: over $100 \mathrm{M}$ website views per year

At $\mathrm{BMC}$, research is always in progress.

Learn more biomedcentral.com/submissions 